\title{
Environment and Trade
}

\author{
MARY DOBBS AND VIVIANE GRAVEY
}

\subsection{Introduction}

As political and legal realities change, one environmental fact remains: the island of Ireland is a single biogeographical and epidemiological unit. The permeable nature of the environment, with transboundary habitats and river basins, creates the potential for positive or negative externalities by actions on either side of the border between Northern Ireland and Ireland, whether intended or accidental. Consequently, for either Northern Ireland or Ireland to achieve a high level of environmental protection requires shared objectives across the island and co-operation at all stages and levels of governance - as reflected in the 1998 Agreement. ${ }^{1}$

The EU provided shared environmental objectives, legal frameworks and governance mechanisms. The shared (or equivalent) standards, for instance regarding sanitary and phytosanitary (SPS) measures, also facilitated the open borders between the UK and the rest of the EU. The 1998 Agreement later enhanced this and also provided for six areas of co-operation in the North-South Ministerial Council, including the environment and the closely related issue of agriculture, as well as establishing several North-South bodies, such as the Loughs Agency overseeing transboundary waters. ${ }^{2} \mathrm{EU}$ membership and the 1998 Agreement together helped facilitate open borders and promoted shared high standards and co-operative environmental governance, ${ }^{3}$ including on the island of Ireland. ${ }^{4}$ Brexit now changes this.

${ }^{1}$ A Hough, 'Brexit, the Good Friday/Belfast Agreement and the Environment: Issues Arising and Possible Solutions', report commissioned by the Environmental Pillar in conjunction with Northern Ireland Environment Link, April 2019, https://nienvironmen tlink.org/cmsfiles/Brexit-GFA-report-FULL.pdf.

2 www.loughs-agency.org/about-us/.

${ }^{3}$ As an area of shared competence, the EU permitted some divergence across the member states and therefore on the island of Ireland.

${ }^{4} \mathrm{M}$ Dobbs, 'The Challenges for the Environment across the Island' in J Mair, $S$ McCabe, N Fowler and L Budd (eds), Brexit and Northern Ireland - Bordering on Confusion? (Bite-Sized Books 2019). 
This chapter examines the implications of Brexit for environmental protection in Northern Ireland, focusing primarily on the Protocol but taking into account other developments in EU-UK relationships and internal UK developments. It outlines (i) the extent to which EU environmental law continues to apply in Northern Ireland, before considering (ii) the potential for regulatory divergence (impacting on both trade and the environment) and (iii) the impacts of border controls. Due to the significance of agriculture for the environment and of the Protocol for agri-food supply chains across the UK and Ireland, the chapter draws on policy examples from both environment and agriculture.

Overall, while some protection continues, it is typically linked to trade. This piecemeal approach leads to a fragmentation of Northern Ireland environmental rules and governance with profound implications for environmental protection. This is especially important in light of the poor environmental record on both sides of the border: neither Ireland nor Northern Ireland has historically been an environmental leader. ${ }^{5}$

\subsection{Continued Compliance with EU Environmental Law?}

Northern Ireland environmental law reflects a complex system of multilevel governance, from the international level to the local level. Prior to Brexit, this included a substantial swathe of EU and EU-derived environmental law, supported by strong EU governance mechanisms, alongside Northern Ireland-originating environmental law. However, following Brexit, the division has shifted and there are increased variations in the nature of environmental law within Northern Ireland. ${ }^{6}$

The UK introduced the concept of 'retained' EU law via the European Union (Withdrawal) Act 2018 (EUWA), whereby all secondary EU law applying up to the end of the transition period would remain in force in domestic law but be given a new legal foundation in UK law, aiming to avoid gaping holes in the UK statute book. However, changes were introduced, for example removal of references to other EU member states and EU institutions. This, on occasion, impacted significantly on

5 B Jack, 'Environmental Law in Northern Ireland' in S McKay and M Murray (eds), Planning Law and Practice in Northern Ireland (Routledge 2017) 154-55; and Case C-494/01, Commission v Ireland [2005] ECR I-3331, ECLI:EU:C:2005:250.

${ }^{6}$ V Gravey and L Whitten, 'The NI Protocol and the Environment: The Implications for Northern Ireland, Ireland and the UK', Environmental Governance Island of Ireland Network Policy briefs 1/2021, March 2021, www.brexitenvironment.co.uk/research-projects/egii/. 
the regulatory regime, for instance through affecting accountability or introducing potential conflicts of interest in the nature conservation regime. ${ }^{7}$ More fundamentally, EU governance regimes could not be replicated. $^{8}$

However, the Protocol achieves something different for Northern Ireland. Article 5(4) provides for the continued application of EU law listed in Annex 2, including subsequent EU laws that amend or replace these laws. ${ }^{9}$ It also provides for the continued application of the EU governance mechanisms to these laws within Northern Ireland, for example the interpretative and enforcement roles of the Commission and the Court of Justice of the European Union (CJEU). As with EU law prior to Brexit, Annex 2 provisions take priority over any potential conflicting domestic law - including any new common frameworks that are intended to apply across the UK. Only if there is no conflict may the common frameworks operate in tandem with this EU law.

Annex 2 is extensive, but focused on trade (including product quality and competitiveness); therefore, environmental laws are typically included only where they impact on trade, rather than for their own sake. ${ }^{10}$ For instance, Annex 2 includes rules on vehicular emissions, pesticides, SPS issues, waste, animal health, food standards and labelling. ${ }^{11}$ In contrast, laws regarding water quality, air pollution and nature conservation are

7 C Brennan and M Dobbs, 'Reality Bites: The Implications of Scrutiny-Free Environmental Law Reform in Northern Ireland after Brexit' (2019) www.brexitenvironment.co.uk/2019/ 03/12/scrutiny-free-environmental-law-northern-ireland/; A Jordan and B Moore, 'Regression by Default? An Analysis of Review and Revision Clauses in Retained EU Environmental Law' (2020) www.brexitenvironment.co.uk/wp-content/uploads/dlm_up loads/2020/05/BrexitenvRegressionbyDefault.pdf.

${ }^{8}$ A Jordan, C Burns and V Gravey, 'Three Brexit Governance Gaps No One Is Talking About' (2017) https://greenallianceblog.org.uk/2017/12/06/three-brexit-governancegaps-no-one-is-talking-about/; M Lee, 'Accountability for Environmental Standards after Brexit' (2017) 19(2) Environmental Law Review 89; and M Lee, 'Brexit and Environmental Protection in the United Kingdom: Governance, Accountability and Law Making' (2018) 36(3) Journal of Energy \& Natural Resources Law 351. See later in this chapter for discussion of developments since.

9 Art 6 WA and Art 13 of the Protocol. Under Art 13(4), the JC may also decide that new EU laws that fall within the scope of the Protocol, but do not technically amend or replace laws listed in the Annexes, can be added to the Protocol.

${ }^{10}$ M Dobbs, 'Northern Ireland's Agricultural Quagmire: How to Develop a Sustainable Agricultural Policy?' in I Antonopoulos, M Bell, A Cavoski and L Petetin (eds), The Governance of Agriculture in Post-Brexit UK (Routledge 2022).

11 Several of these are areas noted as suitable for legislative (UK) common frameworks. However, Northern Ireland must comply with the EU provisions, even if this means conflicting directly with UK primary legislation. 
largely omitted. ${ }^{12}$ This is despite shared environmental challenges and, in some cases, such as the Water Framework Directive, even shared implementation between Ireland and Northern Ireland. ${ }^{13}$ Further, Annex 2 does not create any obligation to comply with the key EU environmental objectives and principles in the Treaty on the Functioning of the European Union (TFEU). However, the Protocol does provide for further laws to be added if the Joint Committee (JC) responsible for overseeing the Protocol decides that this is necessary - this power was used in December 2020, for example, to add the Single Use Plastics Directive ${ }^{14}$ to Annex $2 .^{15}$

The Trade and Cooperation Agreement (TCA) built upon the Protocol, for example with provisions on co-operation on animal welfare, antimicrobial resistance and sustainable food systems, and targets of netzero by $2050 .{ }^{16}$ The TCA's environmental cornerstone is Title XI on the level playing field. Article 7.2 therein introduces a limited obligation of non-regression, whereby neither the EU nor the UK may lower standards overall in a manner that impacts on trade and investment; they must both generally 'strive to increase' their respective levels of protection. However, these obligations are limited in scope, do not mandate alignment (dynamic or otherwise), and are difficult to enforce. ${ }^{17}$ Article 9.4 also provides that where substantial divergence exists (including due to increases in protection) and impacts on trade, the party impacted may take 'rebalancing measures', including unilaterally imposing tariffs. This could pressure the other party to align (upwards), but the clause is very difficult to use and of limited practical value. ${ }^{18}$

12 Counter-examples exist, eg, the inclusion of laws on alien species and the omission of Council Directive 91/676/EEC of 12 December 1991 concerning the protection of waters against pollution caused by nitrates from agricultural sources [1991] OJ L375/1.

13 Directive 2000/60/EC of the European Parliament and of the Council of 23 October 2000 establishing a framework for Community action in the field of water policy [2000] OJ L327/1; C Brennan, M Dobbs and V Gravey, 'Out of the Frying Pan, into the Fire? Environmental Governance Vulnerabilities in Post-Brexit Northern Ireland' (2019) 21(2) Environmental Law Review 84.

${ }^{14}$ Directive (EU) 2019/904 of the European Parliament and of the Council of 5 June 2019 on the reduction of the impact of certain plastic products on the environment [2019] OJL155/1.

${ }^{15}$ Gravey and Whitten (n 6).

16 TCA, Part 2, Titles I and X.

17 V Gravey, 'The Brexit Deal and the Environment: Pretty Ambitious yet Pretty Irrelevant?' (16 February 2021) http://dcubrexitinstitute.eu/2021/02/the-brexit-deal-and-theenvironment/.

18 Ibid. 
Therefore, Northern Ireland's environmental regime encompasses (a) truly domestic law; (b) retained EU law (now slightly amended, without EU governance mechanisms and with the potential for amendments domestically in the future); (c) EU law via the Protocol (with EU governance mechanisms); and (d) limited obligations (including nonregression) related to the level playing field under the TCA. ${ }^{19}$ Many regulatory measures that used to be in the third, EU law, category are now found in the second, retained EU law, category instead, with the Protocol's Annex 2 determining the dividing line between these two categories.

\subsection{Divergence and Decline?}

Brexit therefore introduces the possibility of increased regulatory divergence between the EU and the UK, and also within the UK. The Protocol creates a halfway house for Northern Ireland at the intersection of two unions - at times it may be aligned to the rest of the UK, at times to the $\mathrm{EU}$, and at times to neither. On the one hand, Northern Ireland must comply with EU environmental rules in Annex 2 of the Protocol, so divergence between the EU and the UK will lead to divergence between Northern Ireland and GB. On the other hand, outside Annex 2, where Northern Ireland is not bound to follow EU developments, there is a much greater risk of divergence on the island of Ireland.

This potential for divergence can arise through either action or inaction regarding standards or governance - what Jordan and Moore have called 'regression by default'. ${ }^{20}$ For instance, we have seen that 'retained' EU law has been adapted to function within the UK without EU membership. Amendment of 'retained' EU law has already enabled a first wave of 'simplification', with the removal of 'review and revise' clauses that ensure that EU environmental rules keep abreast with scientific development and are frequently evaluated. ${ }^{21}$ Further 'simplification', or deregulation, can be expected. The UK Environment Bill proposes to grant the Northern Ireland Department of Agriculture, Environment and Rural Affairs and the minister powers to amend existing Northern Ireland environmental law, including on how water quality is to be monitored and evaluated. This, together with the absence of broad

19 Gravey and Whitten (n 6).

20 Jordan and Moore (n 7).

21 Ibid; Brennan and Dobbs (n 7). 
commitment to dynamic alignment, means that retained EU law within Northern Ireland may simply stagnate or indeed be hollowed out, while the EU continues to develop its regimes.

As well as divergence introduced by Northern Ireland or the EU, it is possible that the UK as a whole could introduce changes. Although the environment is a devolved matter in principle, changes could be introduced by way of various mechanisms: via the common frameworks process (although very few environmental areas have been identified as requiring common frameworks); ${ }^{22}$ via changes introduced by the UK government (with or without consent from the devolved administration), as has already taken place using the power to introduce statutory instruments under EUWA 2018; or via requirements that may be imposed resulting from new free trade agreements with non-EU states. There are also potential knock-on effects resulting from the mutual recognition principle in the Internal Market $\mathrm{Act}^{23}$ leading to a lowest common denominator approach regarding future policy across GB. Although it does not apply directly to the Northern Ireland market, the principle applies to any goods for use or sale in GB including from Northern Ireland. ${ }^{24}$ This could create a competitive disadvantage for Northern Ireland producers, thereby incentivizing for instance a lowering in standards of production methods. A further layer of complexity arises when we consider that the Scottish government took powers to keep pace with EU environmental legislation under the Scottish Continuity Act of 2021, meaning that retained EU law may also start to diverge within GB.

However, there are some limits to the divergence possible. First, Northern Ireland (and the UK in respect of Northern Ireland) must comply with the provisions listed in Annex 2 and may not lawfully diverge from these. Environmental provisions within Annex 2, however, remain quite narrow. Second, the TCA's level playing field provisions (especially the non-regression principle and rebalancing mechanisms) may act as a disincentive to major undesirable changes and encourage some minimal upwards alignment, but remain limited in practice. Third, the $\mathrm{UK}$ and the $\mathrm{EU}$ are both signatories to numerous international

22 UK Government, 'Frameworks Analysis 2020: Breakdown of Areas of EU Law that Intersect with Devolved Competence in Scotland, Wales and Northern Ireland' (2020) https://assets.publishing.service.gov.uk/government/uploads/system/uploads/ attachment_data/file/919729/Frameworks-Analysis-2020.pdf.

${ }^{23} \mathrm{~S} 2$.

${ }^{24}$ Under s 11, the principle also applies to Northern Irish 'qualifying goods' in GB, but not to GB goods entering Northern Ireland. 
environmental laws, thereby sharing common objectives and obligations. ${ }^{25}$ However, international environmental law tends to be less specific, with lower standards (if any), and with weaker enforcement mechanisms than EU or national law.

Consequently, some limits on divergence exist, but they are few and far between in practice - divergence can be expected to increase over time, and this potential for divergence risks a decline in environmental protection within Northern Ireland, knock-on impacts outside Northern Ireland due to the permeable nature of the environment, and challenges to cross-border co-operation and governance. Northern Ireland has a dire history of environmental protection, no independent environmental agency (despite renewed commitments in 2020 to such an agency ${ }^{26}$ ), limited resources, and increasing pressures due to issues such as Brexit and Covid-19, on top of an already worrying state of the environment. It is questionable whether there is sufficient political will independently to uphold a high level of environmental protection. Without the EU driving policy and EU governance mechanisms providing back-up enforcement, a decline seems likely, in time with impacts beyond Northern Ireland such as water pollution in transboundary river basins, the degrading of transboundary loughs through dredging, and increased air pollution from burning coal or waste.

Crucially, whether environmental protection in Northern Ireland declines or improves, divergence in itself poses significant challenges for cross-border and all-island co-operation and co-ordination - thereby impacting on the operation of the 1998 Agreement. For instance, the Environment Bill enables significant changes to be introduced to water governance in Northern Ireland. This raises the question of what happens where both jurisdictions seek to protect a river's water quality, but they are measuring different contaminants or with varying methodology or have different understandings of what counts as 'good' status? Divergence does not prevent co-operation, but it makes it more challenging - and, beyond the Annex 2 provisions, Northern Ireland and Ireland will no longer share governance mechanisms, including on dispute resolution. Returning to the example of transboundary waters, the challenges for co-operation are

${ }^{25}$ Eg, the UN Framework Convention on Climate Change (1992), the Biodiversity Convention (1992), the Aarhus Convention (1998) and the Basel Convention on Transboundary Waste (1989).

${ }^{26}$ UK and Irish Governments, New Decade, New Approach (January 2020) https://assets .publishing.service.gov.uk/government/uploads/system/uploads/attachment_data/file/ 856998/2020-01-08_a_new_decade_a_new_approach.pdf. 
exemplified by Article 13 of the EU Water Framework Directive, ${ }^{27}$ which mandates EU member states to co-ordinate with each other regarding transboundary river basins, but only to 'endeavour' to co-operate with third countries. ${ }^{28}$

\subsection{Border Controls and Environmental Impacts?}

While border controls have some negative environmental impacts, for example infrastructure required for border control posts, and delays in transport affecting animal welfare, generally speaking they help enhance environmental protection, for example by facilitating compliance with international environmental obligations. ${ }^{29}$ Further, they help ensure high standards of imports, protecting against diseases and invasive species, for example via SPS controls and requirements for compliance with specific product or process standards. Border controls become critical where there is regulatory divergence.

Any form of Brexit leads to increased border controls. The Protocol and the TCA help determine what controls and checks are required, as well as where they will operate. In light of the 1998 Agreement, the Protocol is intended to ensure no hard border on the island of Ireland and therefore no border control posts, with seemingly open trade between Northern Ireland and the EU. Further, Northern Ireland's 'integral' place within the UK is simultaneously meant to be protected, subject to upholding the Protocol. Numerous hurdles, especially in the form of non-tariff barriers, will arise ${ }^{30}$ indeed, their impacts are already beginning to be seen, ${ }^{31}$ despite the TCA and efforts by the JC to alleviate matters. These vary depending on the route and direction of travel - to or from Northern Ireland, directly from/to GB, or via Ireland.

${ }^{27}$ Directive 2000/60/EC of the European Parliament and of the Council establishing a framework for the Community action in the field of water policy, [2000] OJ L327/1.

${ }^{28}$ W Howarth, 'Brexit and the United Kingdom Water Environment' (2017) 14(3-4) Journal for European Environmental and Planning Law 294.

${ }^{29}$ Eg, under the Convention on International Trade on Endangered Species (1973).

${ }^{30} \mathrm{M}$ Dobbs and L Petetin, 'Agriculture: Environmental, Food and Animal Health Standards' in H Kassin, A Jordan and S Ennis (eds), UK Regulation after Brexit (UK in a Changing Europe 25 February 2021) https://ukandeu.ac.uk/wp-content/uploads/2021/ 02/UK-regulation-after-Brexit.pdf, 51.

31 Eg, S McBride, 'System for Getting Supplies to Northern Ireland May Be Five Days from Collapse Due to Irish Sea Border, Hauliers Warn Michael Gove' (NewsLetter 9 January 2021) www.newsletter.co.uk/news/politics/system-getting-supplies-northern-irelandmay-be-five-days-collapse-due-irish-sea-border-hauliers-warn-michael-gove-3090602. 
Under the Protocol, the simplest trade routes are between Northern Ireland and the EU, including Ireland. Northern Ireland goods are largely treated as EU goods and vice versa, provided they are not going beyond these jurisdictions. The limited regulatory alignment under Annex 2 facilitates this. EU member states may, however, impose measures equivalent to quantitative restrictions (including further environmental criteria) on Northern Ireland goods (exporting norms) without providing justifications. ${ }^{32}$ This encompasses requirements for instance relating to production methods or packaging.

For goods travelling from Northern Ireland to GB, although regulatory divergence between GB and Northern Ireland could lead to checks on such goods, these remain quite minimal in principle, ${ }^{33}$ for example summary export declarations (electronic where possible) and checks to ensure compliance with the Convention on International Trade in Endangered Species of Wild Fauna and Flora (CITES). ${ }^{34}$ Complying with EU rules implementing CITES has been particularly problematic in relation to Lough Neagh eels (Lough Neagh is the largest wild eel fishery in Europe). Traditionally, juvenile (glass) eels are imported from England, and eel meat is then later shipped to retailers across the UK and the EU. While the Protocol protects the Lough Neagh eels fishery's access to the EU market, it does not allow for exporting adult eels outside of the $\mathrm{EU}$ and thus to GB, as it goes against EU CITES rules. ${ }^{35}$

Trade from GB into Northern Ireland is more challenging, ${ }^{36}$ as the Northern Ireland border is effectively an external EU border. Non-tariff barriers and in particular the SPS checks on living organisms or products from these are critical. ${ }^{37}$ Requirements on goods entering Northern Ireland from GB include pre-notification (TRACES), plant or animal

32 Art 5(5) only prohibits quantitative restrictions on such imports, without also specifying measures equivalent to quantitative restrictions or Art 34 TFEU. However, prohibitions on unjustified restrictions under WTO law continue to apply.

33 Section 47 of the Internal Market Act prohibits authorities imposing further hurdles on Northern Ireland goods unless required. See UK Government, 'The Northern Ireland Protocol' (Command Paper, CP346, December 2020) https://assets.publishing.service.gov .uk/government/uploads/system/uploads/attachment_data/file/950601/Northern_Ireland_P rotocol_-_Command_Paper.pdf, pp 7-9.

34 The EU-UK Withdrawal Agreement Explained (slides), 6 July 2020, https://ec.europa.eu/ info/european-union-and-united-kingdom-forging-new-partnership/eu-uk-withdrawal -agreement_en.

35 https://committees.parliament.uk/writtenevidence/23301/pdf/.

36 See Chapter 17.

37 Due to ratification of the SPS Agreement (WTO law) and also Arts 5 and 7 and Annex 2 of the Protocol. 
health certificates, and entry via border control posts to facilitate inspections in a suitable venue. GB goods entering Northern Ireland must comply with EU criteria, but now without the presumption that they meet the relevant standards - instead, this must be demonstrated continuously. These requirements aim to protect the EU and Northern Ireland in the future from a potential decrease in standards or governance in GB - including through contaminated or diseased living organisms potentially brought in from other countries.

These controls and checks introduce substantial administrative burdens, costs and delays - with insufficient infrastructure or staff in Northern Ireland currently to undertake the level of checks required, ${ }^{38}$ especially when the Protocol will be fully implemented. ${ }^{39}$ Substantial delays raise concerns regarding perishable goods (turning to waste) and animal welfare. In April 2021, clerical errors in importation documents led to ponies being delayed at a Northern Ireland port and could have led to their return to GB (with further quarantine periods) or potentially their destruction. A Northern Ireland court ordered their release, based on considerations of animal welfare and 'common sense' - with the required information provided in the meantime. ${ }^{40}$ Furthermore, the increased need for border control posts at the ports has necessitated the rapid construction of such areas, which has its own impact on the environment.

Due to limited logistical capacity, limited financial incentives, or both, some GB suppliers are no longer supplying to Northern Ireland (or to the $\mathrm{EU})^{41}$ - with knock-on effects for downstream producers, consumers and the environment. More suppliers are expected to follow when grace periods end. ${ }^{42}$ With supply chains disrupted, actors downstream need to consider whether to go without or find an alternative source or good. This could provide an opportunity to rethink supply chains or purchases

${ }^{38}$ D Young, 'Permanent Facilities for Brexit Checks at Northern Ireland Ports Will Not Be Ready "until 2023"' Irish Examiner (15 April 2021), www.irishexaminer.com/news/arid40266926.html.

39 Grace periods on certain goods eased the pressure initially. J Curtis, 'Joint Committee Decisions on the Northern Ireland Protocol' (House of Commons Library, BP-9102, 23 December 2020) https://researchbriefings.files.parliament.uk/documents/CBP-9102/ CBP-9102.pdf.

40 BBC News, 'Ponies Detained at Belfast Port over Brexit Forms to Be Released' (22 April 2021) www.bbc.com/news/uk-northern-ireland-56850004.

${ }^{41}$ Dobbs and Petetin (n 30); and G Moriarty, 'Northern Ireland Protocol Is "Extremely Damaging”, DUP Minister Warns' Irish Times (3 November 2020) www.irishtimes.com/ news/ireland/irish-news/northern-ireland-protocol-is-extremely-damaging-dup-minis ter-warns-1.4399090.

42 McBride (n 31). 
and source more environmentally friendly alternatives. ${ }^{43}$ However, it might also incentivize longer supply chains, for example if it becomes easier and swifter to purchase items from distant EU states than GB.

\subsection{Conclusion}

The environment is one of six areas of co-operation for the North-South Ministerial Council, reflecting the importance of cross-border and allisland environmental governance. However, the Protocol's and the TCA's provisions focus on the environment only to a limited extent in particular via Annex 2, the level playing field provisions and border controls. While these are valuable provisions, they do not equate to the level of protection provided by EU membership; divergence is likely, and border controls could also pose environmental harms.

The fragmentation of environmental law, in a jurisdiction with a long history of lack of administrative capacity and political will to act on environmental challenges, is particularly concerning. This fragmentation not only increases the workload of the administration; it also risks further politicization of environmental action, increases the likelihood of a decline in environmental governance, and makes it more complex for environmental groups to hold decision-makers accountable.

While some level of border control is necessary due to Brexit, this, along with the potential for divergence and environmental degradation, can be mitigated; technical instruments in the 1998 Agreement, the TCA, the Protocol and the Internal Market Act exist to manage divergence and facilitate co-operation. The successful use of such options depends on whether the political will exists within the UK (including Northern Ireland) and the EU (including Ireland).

${ }^{43}$ Covid-19 disrupted supply chains globally and could provide useful insights, both positive and negative. L Petetin, 'The COVID-19 Crisis: An Opportunity to Integrate Food Democracy into Post-Pandemic Food Systems' (2020) 11(S2) European Journal of Risk Regulation 326. 